\title{
Prevention and Prophylaxis of Tick Bites and Tick-Borne Related Diseases
}

\author{
Lara Garcia-Alvarez, Ana Maria Palomar and Jose Antonio Oteo
}

Department of Infectious Diseases Hospital, Center of Rickettsioses and Arthropod-Borne Diseases, San Pedro-Center for Biomedical Research of La Rioja (CIBIR), Logroño, La Rioja, Spain

Received 2013-09-10, Revised 2013-11-04; Accepted 2013-11-05

\begin{abstract}
Ticks are obligate haematophagous arthropods present all over the world able to produce human diseases. Several factors have increased the abundance, circulation and distribution of the pathogens transmitted by ticks, contributing to the change in the vector-borne diseases epidemiology in the last years. This review collects the most important measures for the prevention and prophylaxis of tick-borne diseases. The preexposition measures to avoid tick-borne diseases are based on the prevention of tick bites by avoiding tickinfested areas, using of protective clothing, repellents and controlling tick populations by physical, mechanical, biological and chemical methods. It is also reviewed other measures as the utility of educational programs and the use of human vaccines. On the other hand, we also review some key aspects referred to the measures to carry out after tick bites as how to remove a tick correctly and the utility of making an antibiotic prophylaxis.
\end{abstract}

Keywords: Prevention, Prophylaxis, Ticks, Tick-Borne Diseases

\section{INTRODUCTION}

Ticks are obligate haematophagous arthropods present all over the world that require an animal host to survive. They feed on different species of mammals, birds and reptiles. Some tick species can bite people and produce several diseases of Public Health importance by different mechanisms (Table 1). There are more than 850 tick species worldwide but only about 45 of them are involved in the transmission of human diseases (Oteo et al., 2001; Stafford, 2004). Table 2 shows the main diseases, vectors, distribution and disease agents related with ticks.

Ticks able to produce human diseases are divided in two families: Ixodidae (hard-ticks and main vectors of infectious diseases in the industrialized world), Argasidae (soft-ticks that are generally nest inhabitants associated with birds, bats or rodents and that are associated to poverty and rural areas mainly in non- developed countries). There is a third family called Nuttalliellidae, only present in the southeast of Africa, that does not cause disease. Tick life cycle has four stages: egg, larvae, nymph and adult (female or male). The last three stages can bite humans and transmit an infectious disease (Oteo et al., 2001; Stafford, 2004; Marquez-Jimenez et al., 2005) (Fig. 1).

There are good up-dates and clinical reviews about the most important tick-borne diseases around the world for the diagnosis and clinical management (Steere, 2001; Parola et al., 2005; Oteo and Brouqui, 2005; Oteo and Portillo, 2012; Walker et al., 2008; Dobler, 2010; Labruna et al., 2011; Dantas-Torres et al., 2012). Several factors as climate change or deforestation among others, have increased the abundance, circulation and distribution of the pathogens transmitted by ticks contributing to the change in the vector-borne diseases epidemiology in the last years (Parola et al., 2008; Beugnet and Marie, 2009; Day, 2011).

Corresponding Author: Jose Antonio Oteo, Department of Infectious Diseases Hospital, Center of Rickettsioses and ArthropodBorne Diseases, San Pedro-Center for Biomedical Research of La Rioja (CIBIR), Logroño, La Rioja, Spain 
Lara Garcia-Alvarez et al. / American Journal of Infectious Diseases 9 (3): 104-116, 2013

Table 1. Pathogenic mechanisms that cause tick diseases

\begin{tabular}{ll}
\hline Mechanism & Disease or agent \\
\hline Blood loss & Anemia \\
Inoculation of microorganisms & Virus, bacteria, protozoa, funghi and nematodes \\
Inoculation of neurotoxins & Tick paralysis \\
Hypersensitivity & Pruritic papules, lymphocytomas, urticaria and anaphylasis \\
Local traumatism and loss of skin integrity & Pyogenic superinfection of skin flora \\
\hline
\end{tabular}

Table 2. Main tick-borne infectious diseases

\begin{tabular}{|c|c|c|c|}
\hline Disease & Etiological agent & Main vector & Geographical distribution \\
\hline Mediterranean Spotted Fever & Rickettsia conorii subsp. conorii & Rhipicephalus sanguineus complex & Mediterranean Area \\
\hline Israeli Spotted Fever & Rickettsia conorii subsp. israelensis & $R$. sanguineus & Israel, Portugal, Italy \\
\hline Astrachan Fever & Rickettsia conorii subsp. caspia & $\begin{array}{l}\text { Rhipicephalus pumilio } \\
\text { R. sanguineus }\end{array}$ & Astrachan Kosovo, Chad \\
\hline Indian tick typhus & Rickettsia conorii subsp. indica & $\begin{array}{l}R . \text { sanguineus } \\
\text { Boophilus microplus } \\
\text { Haemaphysalis leachii }\end{array}$ & India, Pakistan \\
\hline Rocky Mountain Spotted Fever & Rickettsia rickettsii & $\begin{array}{l}\text { Dermacentor andersoni } \\
\text { Dermacentor variabilis } \\
\text { Amblyomma aureolatum } \\
\text { Amblyomma canjennense } \\
\text { R. sanguineus }\end{array}$ & America \\
\hline $\begin{array}{l}\text { Lymphangitis-associated } \\
\text { rickettsiosis (LAR) }\end{array}$ & $\begin{array}{l}\text { Rickettsia sibirica subsp. } \\
\text { mongolitimonae }\end{array}$ & $\begin{array}{l}\text { Hyalomma asiaticum } \\
\text { Hyalomma truncatum } \\
\text { Hyalomma anatolicum excavatum } \\
\text { Rhipicephalus pussillus }\end{array}$ & South Europe, Africa \\
\hline Siberian Tick Thypus & $\begin{array}{l}\text { Rickettsia sibirica } \\
\text { subsp. sibirica }\end{array}$ & $\begin{array}{l}\text { Dermacentor nuttalli } \\
\text { Dermacentor marginatus } \\
\text { Dermacentor silvarum } \\
\text { Dermacentor pictus } \\
\text { Dermacentor sinicus } \\
\text { Dermacentor auratus } \\
\text { Haemaphysalis concinna }\end{array}$ & Siberia, Mongolia \\
\hline Queensland Tick Typhus & Rickettsia australis & $\begin{array}{l}\text { Ixodes holocyclus } \\
\text { Ixodes tasmani } \\
\text { Ixodes cornuatus }\end{array}$ & Australia \\
\hline Flinder's Islands Spotted Fever & Rickettsia honei & $\begin{array}{l}\text { Amblyomma hydrosauri } \\
\text { Ixodes granulatus }\end{array}$ & Australia, Thailand, Nepal \\
\hline Australian Spotted Fever & Rickettsia marmionii & $\begin{array}{l}\text { Haemaphysalis novaeguinae } \\
\text { Ixodes holocytus }\end{array}$ & Australia \\
\hline African tick bite fever & Rickettsia africae & $\begin{array}{l}\text { Amblyomma hebraeum } \\
\text { Amblyomma variegatum }\end{array}$ & $\begin{array}{l}\text { Saharan Africa, Guadalupe, } \\
\text { Turkey, Oceania }\end{array}$ \\
\hline Japanesse Spotted Fever & Rickettsia japonica & $\begin{array}{l}\text { Haemaphysalis flava } \\
\text { Haemaphysalis hystericis } \\
\text { Haemaphysalis longicornis } \\
\text { Dermacentor taiwanensis } \\
\text { Ixodes ovatus }\end{array}$ & Japan, Thailand \\
\hline Far Eastern Spotted Fever & Rickettsia heilongjiangensis & $\begin{array}{l}\text { D. silvarum } \\
\text { H. concinna } \\
\text { Haemaphysalis japonica douglasi }\end{array}$ & Asia \\
\hline Innominate & Rickettsia helvetica & Ixodes ricinus & Europe, Central Asia \\
\hline Innominate & Rickettsia aeschlimannii & Hyalomma marginatum & Mediterranean area, Africa \\
\hline Innominate & Rickettsia parkeri & $\begin{array}{l}\text { Amblyomma maculatum (triste) } \\
\text { Amblyomma americanum }\end{array}$ & America \\
\hline Innominate & Rickettsia monacensis & I. ricinus & Europe \\
\hline Innominate & Rickettsia massiliae & $\begin{array}{l}\text { R. sanguineus } \\
\text { Rhipicephalus turanicus }\end{array}$ & Mediterranea Area, America \\
\hline $\begin{array}{l}\text { Dermacentor-Borne Necrosis } \\
\text { Erythema and Lymphadenopathy/ }\end{array}$ & Rickettsia slovaca & D. marginatus & Europe \\
\hline $\begin{array}{l}\text { TIck-Borne Lymphadenopathy } \\
\text { (DEBONEL/TIBOLA) }\end{array}$ & $\begin{array}{l}\text { Candidatus Rickettsia rioja } \\
\text { Rickettsia raoultii }\end{array}$ & Dermacentor reticulatus & \\
\hline Lyme borreliosis & Borrelia burgdorferi sensu lato & $\begin{array}{l}\text { I. ricinus } \\
\text { Ixodes scapularis } \\
\text { Ixodes pacificus } \\
\text { Ixodes persulcatus }\end{array}$ & $\begin{array}{l}\text { Europe } \\
\text { America } \\
\text { Asia }\end{array}$ \\
\hline
\end{tabular}




\begin{tabular}{|c|c|c|c|}
\hline $\begin{array}{l}\text { Relapsing fever Borrelia } \\
\text { infection }\end{array}$ & Borrelia miyamotoi & $\begin{array}{l}\text { I. ricinus } \\
\text { I. scapularis } \\
\text { I. pacificus } \\
\text { I. persulcatus }\end{array}$ & $\begin{array}{l}\text { Europe } \\
\text { North America } \\
\text { Asia }\end{array}$ \\
\hline Human Monocytic & Ehrlichia chaffeensis & A. americanum & USA \\
\hline Ehrlichiosis Human & Anaplasma phagocytophilum & I. scapularis & North America \\
\hline Granulocytic Anaplasmosis & & $\begin{array}{l}\text { I. pacificus } \\
\text { I. ricinus } \\
\text { I. persulcatus }\end{array}$ & $\begin{array}{l}\text { Europe } \\
\text { Asia }\end{array}$ \\
\hline Human Granulocytic & Ehrlichia ewingii & A. americanum & North America, Africa, Asia \\
\hline Ehrlichiosis Innominate & $\begin{array}{l}\text { Candidatus Neoherlichia } \\
\text { mikurensis }\end{array}$ & $\begin{array}{l}\text { I. ovatus } \\
\text { I. persulcatus }\end{array}$ & Asia \\
\hline & & I. ricinus & Europe \\
\hline Tularemia & Francisella tularensis & Ixodidae & America, Europe, Asia \\
\hline Babesiosis & $\begin{array}{l}\text { Babesia divergens } \\
\text { Babesia microti }\end{array}$ & $\begin{array}{l}\text { I. ricinus } \\
\text { I. scapularis }\end{array}$ & $\begin{array}{l}\text { Europe } \\
\text { North America }\end{array}$ \\
\hline Crimean-Congo & Crimean-Congo Hemorrhagic & Hy. marginatum & Africa, Europe, Asia \\
\hline Hemorrhagic Fever & Fever virus (Nairovirus gender) & D. andersoni & North America \\
\hline Colorado tick fever & Colorado tick fever virus (Coltivirus gender) & & \\
\hline Powassan encephalitis & Powassan virus (Flavivirus gender) & $\begin{array}{l}\text { I. cookei } \\
\text { I. sxapularis }\end{array}$ & $\begin{array}{l}\text { North America } \\
\text { Rusia }\end{array}$ \\
\hline Innominate & Eyach virus (Coltivirus gender) & I. ricinus & Europe \\
\hline Tick-borne encephalitis & Tick-borne encephalitis virus (Flavivirus gender) & $\begin{array}{l}\text { I. ricinus } \\
\text { I. persulcatus }\end{array}$ & $\begin{array}{l}\text { Europe } \\
\text { Europe, Asia }\end{array}$ \\
\hline Louping ill & Louping ill virus (Flavivirus gender) & I. ricinus & Europe \\
\hline Omsk Hemorrhagic Fever & $\begin{array}{l}\text { Omsk Hemorrhagic Fever } \\
\text { virus (Flavivirus gender) }\end{array}$ & $\begin{array}{l}\text { D. maginatus } \\
\text { D. reticulatus } \\
\text { I. persulcatus }\end{array}$ & Asia \\
\hline Kyasanur forest disease & Kyasanur forest disease virus (Flavivirus gender) & Haemaphysalis spinigera & India, Sri Lanka \\
\hline Innominate & Bhanja virus & H. punctata & Africa, Asia, Europe \\
\hline Innominate & Dhori virus (Asfarviridae Family) & $\begin{array}{l}\text { Hy. marginatum } \\
\text { Hyalomma dromedarii }\end{array}$ & Europe, Asia, Africa \\
\hline Innominate & Thogoto virus (Orthomyxoviridae Family) & $\begin{array}{l}\text { Rhipicephalus spp. } \\
\text { Boophilus spp. } \\
\text { Hyalomma spp. } \\
\text { A. variegatum }\end{array}$ & Africa, Europe \\
\hline Innominate & Avalon virus (Nairovirus gender) & $\begin{array}{l}\text { I. uriae } \\
\text { I. signatus }\end{array}$ & Canada, Russia \\
\hline $\begin{array}{l}\text { Severe fever with } \\
\text { thrombocytopenia syndrome }\end{array}$ & $\begin{array}{l}\text { Severe fever with thrombocytopenia } \\
\text { syndrome virus (Phlebovirus gender) }\end{array}$ & H. longicornis & China \\
\hline Innominate & Heartland virus (Phlebovirus gender) & A. americanum & USA \\
\hline
\end{tabular}

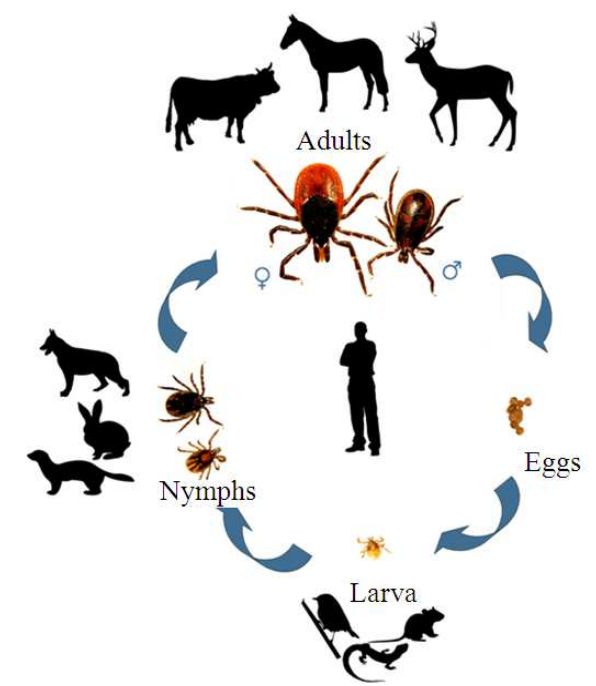

Fig. 1. Life cycle of the hard tick Ixodes ricinus
Tick bites do not mean that a person will get necessary a disease or infection. To acquire a tick-borne disease certain conditions must be met (Oteo et al., 2001):

- It is necessary that the tick is infected with the agent able to produce a disease for which requires that the reservoir is present (birds, mammals... or even the tick in the case of rickettsioses and others)

- The tick species has to be competent for the transmission

- The patient has to be susceptible to the agent that produces the disease

Moreover, most of the tick bites are uncomplicated and only produce cutaneous pruritic reactions and a prompt removal of an attached tick can reduce the risk of getting an infection as occurs with Lyme disease (Oteo et al., 2001). It is easy to understand that the risk increases with the tick feeding and engorging. Nevertheless, there are few studies 
based in animal (De Silva and Fikrig, 1995; Lindsay et al., 1997; Katavolos et al., 1998; Zivkovic et al., 2007; Horka et al., 2009) or in vitro (Krober and Guerin, 2007; Hojgaard et al., 2008) models that evaluate the time of feeding for the transmission of tick-borne agents.

The aim of this review is to make a compilation of the "State of the Art" about tick-borne diseases prophylaxis emphasizing in pre-exposition and postexposition measures.

\section{PRE-EXPOSITION MEASURES}

The best method to avoid tick-borne diseases is preventing tick bites. There are some steps than can be taken to diminish, eliminate or avoid tick bites.

\subsection{Avoidance of Tick-Infested Areas}

One of the measures to prevent tick bites is to avoid high risk habitats during the season peaks of activity of the ticks (Piesman and Eisen, 2008). In case of going to the countryside, being especially alert when doing some activities in tick-infested habitats (hiking, camping), in these cases, keeping to the center of trails could minimize contact with adjacent vegetation were ticks are more abundant (Fig. 2).

\subsection{Use of Protective Clothing}

Wearing protective clothing that limits the contact of ticks with the body can be very effective to avoid tick attachment. Studies carried out by Vazquez et al. (2008) on a conducted matched case-control study for nearly three years, showed that the use protective clothing outdoors was $40 \%$ effective against tick-borne diseases as Lyme disease.

It is advisable wearing light-colored clothing to detect the arthropod before attached to the skin, decrease the risk that a tick finds a feeding site avoiding the exposure of the body surface wearing cap, long trousers tucked into the socks, long-sleeved shirt tucked into the trousers and do not wear sandals or open-toed shoes (Fig. 3). It is desirable to inspect for unattached ticks in on clothing because they can turn into a later tick bite. Depending on the species, ticks can survive for long temps, therefore wash and dry clothing is a good practice (Oteo et al., 2001; Stafford, 2004; Piesman and Eisen, 2008; Clark and Hu, 2008).

\subsection{Use of Repellents}

The use of repellents has also demonstrated the decrease of tick bites incidence when applied to clothes or bare skin. The same study of Vazquez et al. (2008) showed that the use of repellents on clothing or skin had a $20 \%$ of effectiveness.
A repellent has to achieve disruption of the contact between the host and the arthropod parasite, death of the arthropod, prevention of the feeding and interference with egg fertility and development of its life cycle stage (Halos et al., 2012). A good repellent should be effective against various arthropods, no irritating after topical administration, with pleasant odor or odorless, persistent after washing and economic (Oteo et al., 2001). Permethrin based products and DEET (N,N-diethyl-metatoluamide) have shown being efficacious repellents. Others as picardin have also been used (Steere, 2001).

Ticks repellents containing DEET are available in a wide variety of topical formulas providing most of them up to $12 \mathrm{~h}$ of protection (optimal concentration ranges: $15-33 \%$ ). It has been shown being the most effective and broad spectrum repellent discovered (Stafford, 2004). There are repellents for cutaneous use, for the application on clothing or for both uses. Due to permethrin toxicity it has to be used on clothing, it could be effective for up several weeks and even supports the washings. The effectiveness of this product has been demonstrated. So, the use of permethrin-treated clothing reduces significantly tick bites and tick-borne pathogen transmission (Miller et al., 2011; Vaughn and Meshnick, 2011). Both repellents are also effective against insects such as mosquitoes, flies or fleas (Vazquez et al., 2008). However, despite these products are reasonable safe to use many people display certain toxicity. This fact has misguided in the use of repellents based on natural products as garlic, citronella, eucalyptus oil, geranium oil, lavender oil or Alaska yellow cedar oil (e.g., citriodiol or p-menthane-3,8-diol available on the market as a tick repellent) (Piesman and Eisen, 2008; Clark and Hu, 2008).

\subsection{Tick Control}

Actually, tick control is aimed on the concept of integrated pest management. Nevertheless, to eliminate absolutely ticks in infested areas is almost impossible. The objective is controlling and reducing tick and tickinfected populations with the aim of reducing the number of human tick-bites and human diseases with the resources available. Integrated pest management involves economic, biological and sociological costs and benefits (Stafford, 2004; Walker, 2011).

\subsection{Physical and Mechanical Control}

In order to the landscape management, modifications can decrease the abundance of ticks present in the yard by the creation of unattractive environment for ticks and their hosts. Some strategies that could help are clearing leaf litter and woodchip barriers, increase sunlight and decrease humidity may produce a less hospitable area for ticks. 


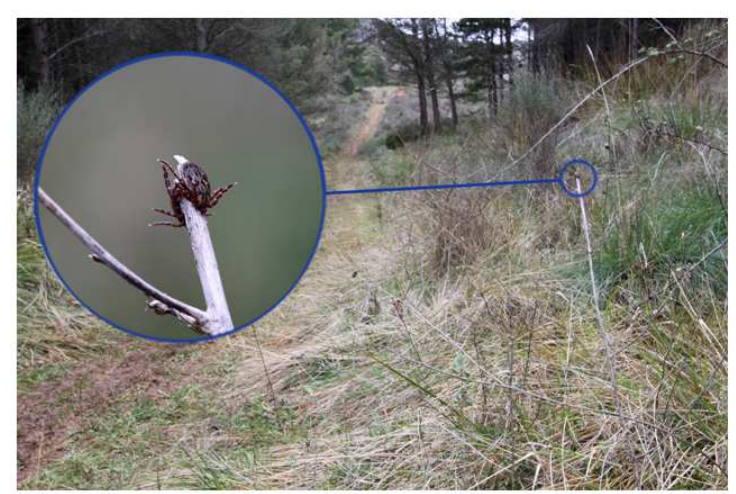

Fig. 2. Detail of the present of the tick Dermacentor marginatus in the adjacent vegetation of a trail

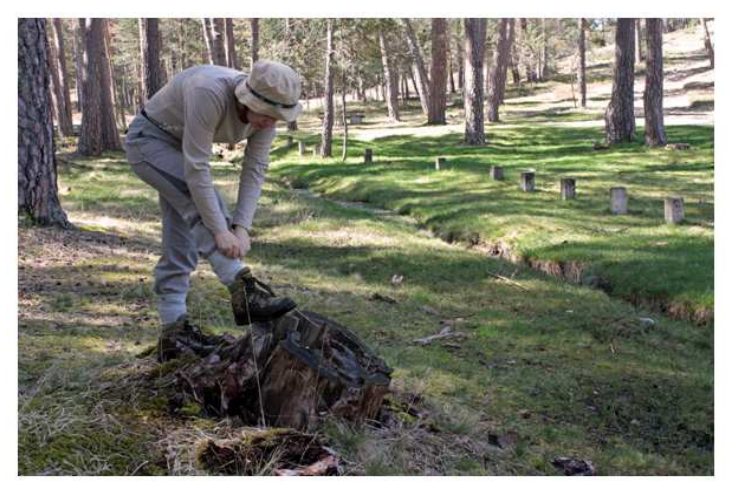

Fig. 3. Example of the recommended clothing for preventing a tick attached

Therefore, in the case of residential tick management, mow the lawn, prune trees and remove leaf litter, brush along edges of the grass, driveways and stonewalls among other strategies could reduce tick population adjacent to homes (Stafford, 2004). These measures can also help to decrease the number of rodents and other potential reservoirs of infectious diseases agents.

Other strategies based on environmental management, as controlled burns, have been carried out with the aim of reducing the abundance of some ticks. Years ago, these strategies shown to reduce the abundance of some ticks on their different life stages (Smith et al., 1946; Rogers, 1953; Hoch et al., 1972; Drew et al., 1985; Wilson, 1986; Mather et al., 1993; Stafford et al., 1998). However, despite controlled burns of vegetation have initially shown to reduce the number of ticks and the suitable vegetation for tick habitat, the effects of this practice seem to be only temporary (Wilson, 1986; Stafford et al., 1998). Furthermore, the effect of vegetative destruction resulted in a reduction in the abundance of nymphal and larval stages, but the abundance of adult ticks was not affected in the same degree (Hoch et al., 1972; Stafford et al., 1998). More recent studies have found that controlled burns have the potential of increasing the abundance of some ticks due to an increase of their preeminent host, as the case of whitetailed deer for Amblyomma americanum (Allan, 2009). These results suggest that the attraction of the host to postburn habitats could result in recolonization rates of ticks causing a higher abundance than before the controlled burn (Allan, 2009). The implementation of this environmental management does not appear effective unless done with a high frequency (Stafford et al., 1998; Allan, 2009).

\subsection{Biological Control}

Different methods for biological control of ticks are available. The use of natural predators as spiders, ants and beetles, some parasites as mites, nematodes or other insects, bacterial pathogens of ticks or sterilized males have been used (Samish and Rehacek, 1999).

The use of pheromones and other semichemicals compounds as kairomones and tick allomones could be also interesting for tick control when applied to tick-infested vegetation or directly to the body surfaces of livestock or companion animals (Sonenshine, 2004; 2006).

One strategy to the management of ticks is the managing of their host such as deer, birds and small rodent activity. In reference to deer, some studies have shown that reduction of deer can reduce tick abundance (Rand et al., 2004). However, this lethal management is controversial not only because of the ethical aspects in this respect, also due to the results showed by others authors (Jordan et al., 2007). New approaches less controversial have been carried out by the U.S. Department of Agriculture to kill ticks of deer when feeding using chemical products (Stafford, 2004).

Rodents and birds have been shown to be able to transport ticks to the properties. Birds are the main hosts form some ticks and they could spread infected ticks able to cause human diseases as Lyme disease, anaplasmosis, rickettsioses and others (Hubalek, 2004; Palomar et al., 2012; 2013). Some studies suggest the involvement of birds in the cycle of human tick-borne diseases and the role of birds on the dispersion of vectors and microorganisms (Palomar et al., 2012). Place feeders or birdhouses away from houses and establish feeders when natural foods are limited, on winter and late fall, are some strategies oriented to the bird management (Stafford, 2004).

Regarding to mice, first rodent-targeted were cottonballs treated with permethrin on a cardboard tube 
(Stafford, 2004). However the effectiveness of this method depended on the cotton collected as nesting material from the tubes around the mouse habitat (Stafford, 2004). The use of rodent-targeted bait boxes containing fipronil have been shown to eliminate ticks on mice (Stafford, 2004; Piesman, 2006). Those boxes are sealed, child resistant and containing food blocks and an applicator with $0.70 \%$ fipronil and the impact of them on tick population accumulates over time (Piesman, 2006).

\subsection{Chemical Control and Deworming Animals}

Tick control with chemical acaricides has been used since the end of the nineteenth century with the discovery of some substances such as arsenical solutions (George et al., 2004). Although different kinds of acaricides have been developed, many of them have shown toxicity for humans, animals or for the environment (such as DDT). Moreover, ticks have developed resistance to several of those products (WHO, 1992; George et al., 2004; Mendes et al., 2011). Chemical acaricides could be applicated to vegetation or to hosts (wild or domestic). Those products act against free-living stages of ticks when they are applied to vegetation layers, acting over determinate stages depending on the tick species and the season. In many cases, the fumigation of the vegetation has shown to be effective for tick population reduction and the potential reduction for human/tick encounters in high-risk areas (Stafford, 1991; Schulze et al., 1992; 1994; 2005; 2007; 2008; Piesman and Eisen, 2008). This technique has been referred in public health programs (Korenberg and Kovalevskii, 1999) but deworming of animals is more common to control tick populations (Piesman and Eisen, 2008; Walker, 2011; Ahoussou et al., 2010).

As has been mentioned before, a tick bite does not ensure the transmission of a disease in humans and therefore in other animals. However, the contact between humans and parasitized domestic animals could increase the risk of a tick-borne disease acquisition. Generally, ticks have been evolved as parasites of wild animals but, the increase of frequent into wooded areas and others wild environments and the closer association of wild animals with human activity has increased the prevalence of transmission of tick borne diseases to pets and their owners (Shaw et al., 2001). These facts are some of the responsible that cause changes in the epidemiology. Transport facilities by earth, sea and air have increased in the last years causing a big animal movement because of the tourism or the animal production. The open air activities, the creation of recreational areas in the cities and the increase of private garden also contribute to establish of tick populations and the peri-domestic hosts as rodents (Beugnet and Marie, 2009). Companion animals can act as sentinels of these infectious diseases. Transmission of zoonotic infectious diseases depends of the lifestyle of the pet and livestock and it is influenced by vaccination and parasite control.

The tick control in domestic animals must be done correctly to avoid animal, environmental or food toxicity, even in humans, chemical resistance in ticks or unnecessary costs (Walker, 2011). Treatments with chemical acaricides are diverse and they must be applied depending on the kind of substances, formulation, tick species, season. Usually, the choice method is direct application of chemical acaricides to host animals (Mondal et al., 2013). Formamidines, chlordimeform, clenpyrin, chloromethiuron and amitraz are effective against ticks (George et al., 2004).

To control tick populations on livestock is necessary the involvement of the large majority of farmers in an area (Walker, 2011). Moreover, tick control on livestock and wildlife is influenced each other. Livestock and wildlife share habitats and accordingly, some parasites and diseases (Walker, 2011; Miller et al., 2012). For this reason, a good tick control management must be contemplated in both, livestock and wild animals.

The main tick-borne infectious disease transmitted by companion animals as dogs and cats that also infect man are: borreliosis, bartonellosis, ehrlichiosis, rickettsiosis, anaplasmosis, tularaemia, coxiellosis, tick-borne encephalitis and Louping ill (Day, 2011). Although the tick eradication is almost impossible in many situations due to the maintenance of the tick life cycle on the hosts, the most effective preventative measure arises in the use of effective long-acting acaricides as permethrin, amitraz or fipronil or lindano according to the manufacturers instructions (Shaw et al., 2001; Berrada and Telford, 2009). Sometimes, topical acaricides will not work preventing tick infestation therefore, control should be based on the understanding tick ecology, tick distribution and seasonal occurrence (Dryden and Payne, 2004).

Vaccines can also be used but currently commercially available only exists for canine borreliosis and babesiosis (Ma et al., 1996; Schetters et al., 1997; 2007; Schetters, 2005). Others experimental vaccines like the one against canine monocytic ehrlichiosis, not commercially available, have been reported (Shaw et al., 2001). Vaccines should be considered for those animals that are frequently exposed to infested habitats of risk. Obviously, prevention on cats is relatively easy because they should remain indoors (Berrada and Telford, 2009). 


\subsection{Educational Training}

Educational programs could be a good tool to decrease the risk of acquiring a tick borne infectious disease. There are institutional programs that alert on tick infested areas all over the world (Fig. 4). In this term, several groups have developed different studies to evaluate the power of the educational programs. Daltroy et al. (2007) realized a randomized study in which analyzed the impact of an educational training in tick prevention in a group of ferry passengers. They observed that the risk of tick-borne infection was clearly reduced among those who visit the same place for longer than two weeks. Also, those receiving the educational program were more likely to spend less time in infested areas, use repellents, wear protective clothing and perform tick checks than controls (Daltroy et al., 2007). Other study carried out in Baltimore (Maryland), showed that people receiving tick education were more likely to perform tick checks and to use repellents, however, there were not differences in serologic response respecting to the group of people how received general health education (Malouin et al., 2003).

\subsection{Human Vaccines}

Vaccines were developed in past for preventing rickettsiosis but to date commercial vaccines are not available for humans.

In the early 1900s two Lyme diseases vaccines were developed LYMErix developed by Smith-Kline Beecham (now known as GlaxoSmithKline) and ImuLyme by PasteurMérieux-Connaught (Poland, 2011; Shen et al., 2011). Both were able to prevent Lyme disease but not for others zoonotic diseases that could coinfect the same tick (babesia and ehrlichia infections). However, despite their efficacy and safety for Lyme disease, one of them the first was withdrawn after only three years in the market (in February 2002) and the other before the regulatory review (Shen et al., 2011; Aronowitz, 2012). In both vaccines the action mechanism of them for protection again Lyme disease was based on the outer surface protein A (OspA) of $B$. burgdorferi. The subsequent develop of bactericidal antibodies able to bind and neutralize viable spirochetes when tick is feeding blood (Poland, 2011). Both vaccines were tested in more than 10,000 participants each after phase III of clinical trials, showing that both of them reduced the number of clinical cases of Lyme disease (Shen et al., 2011). The advisable administration of LYMErix (30 $\mu \mathrm{g}, \mathrm{i} . \mathrm{m}$.) was series of 3 injections at 0,1 and 12 months followed by 2 booster doses at 1 and 12 months after primary vaccination. Results after phase III of clinical trial showed a $76 \%$ efficacy in preventing Lyme disease confirmed by laboratory assays and $100 \%$ in the prevention of the asymptomatic disease in the population that completed the 3 series of doses (Steere et al., 1998). The recommendation from the Advisory Committee on Immunization Practices (ACIP) of the Centers for Disease Control and Prevention (CDC) for the use of this vaccine was for persons from 15 to 70 years who lived or worked in infected areas (CDC, 1999), however vaccine was not recommended for person who had animals or no exposure to ticks infested areas. Meanwhile, ImuLyme was evaluated by Sigal et al. (1998) according to the same administration at 0,1 and 12 months showed an efficacy of the $68 \%$ after two injections and $92 \%$ after the third one. Interesting is the fact that this last vaccine was less effective for subjects older than 60 years of age.

These vaccines were only used in United Estates. In Europe, never was indicated due to the greater sequence diversity in the OspA among strains of the bacteria circulating (Clark and $\mathrm{Hu}, 2008$ ). Finally, the human OspA vaccine was withdrawn from the market due to the low sales because of the expensive cost, the need of frequent revaccination and the relationship that involved the vaccine with the development of resistant arthritis related with immune response in certain patients (Oteo et al., 2001; Clark and $\mathrm{Hu}, 2008$ ). Furthermore, the effectiveness of the vaccines was unknown in pregnant women, patients younger than 15 years old or older than 70, immunocompromised patients or in not endemic areas (CDC, 1999; Oteo et al., 2001).

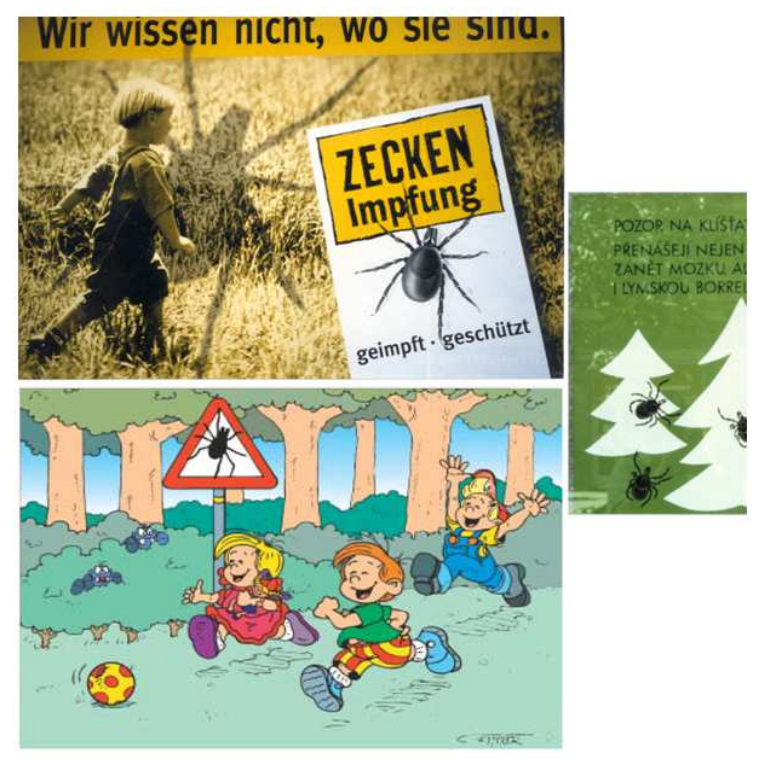

Fig. 4. Warning advertisement of tick presence 
Military have also contributed in this sense to the development of vaccines. During the World War II, the Joint U.S. Typhus commission was formed and one of their recommendations was the immunization with the Cox-type vaccine. However, this vaccine no longer meets modern standards so there is no Food and Drug Administration-licensed typhus vaccine. In the early 1980s the Naval Medical Research Institute developed an effective modern subunit vaccine (Bavaro et al., 2005). Furthermore, the first modern vaccine for Rocky Mountain spotted fever was also developed by the U.S. Army but despite it effective immunogen it result in reactogenicity among vaccines (Bavaro et al., 2005). To date, there are no licensed rickettsial vaccines by the Food and Drug Administration (Bavaro et al., 2005).

In reference with other tick borne diseases there is only currently available one vaccine approved for TickBorne Encephalitis (TBE), caused for a flavivirus endemic in Europe, especially prevalent in Eastern and Central Europe. There are different forms of the vaccine available that use a standard dose (an initial injection, a second dose in the next 1-3 months and a third dose 9-12 months after the second one) and an accelerated dose, used mainly in travellers ( 3 doses on days 0, 7 and 21). The use of this vaccine has shown being very effective in reducing the incidence of the disease. There was also a TBE immunoglobulin used in Russia as pre-exposure prophylaxis and post-exposure, however it was withdrawn due to the possible adverse effects (Clark and $\mathrm{Hu}, 2008$ ).

To our knowledge, there are not others currently vaccines for the prevention of other tick-borne infections as anaplasmosis, babesiosis, or rickettsioses (Oteo et al., 2001; Clark and Hu, 2008). Thereby, the development of new strategies and targets for the design of new vaccines could represent a major advance in the prevention and prophylaxis of tick-borne diseases.

\section{POST-EXPOSITION MEASURES}

\subsection{Tick Removal}

Although using the appropriate clothing tick bites can occur and they are usually painless, making important to do an exhaustive exploration of the entire body in order to look for any attached ticks and remove them. When a person present an attach tick it is necessary to remove it from the skin as soon as possible. Generally, a tick require $>24-48 \mathrm{~h}$ for the transmission of some diseases, thereby this risk increases with the duration of attachment. For example, in the case of the transmission of $B$. burgdorferi it is needed $36-72 \mathrm{~h}$ of tick feeding to inoculate the spirochete, however, the transmission of Ehrlichia spp. or the agent of the Rocky Mountain Spotted Fever can occur in shorter time periods (Piesman et al., 1987; Oteo et al., 2001).

The use of tweezers or forceps to remove ticks has been shown significantly decrease the risk of complications associated to the tick-bite or the infection with the microorganisms they transmit (Oteo et al., 1996). Matuschka and Spielman (1992) also considered the use of tweezers as the choice method. Others popular methods for removing ticks from skin as manual extraction, oil, vaseline, petroleum, lighted cigarettes,... despite being effective methods for removing ticks from the skin, they are associated with an increase of complications and transmission of infectious agents (Oteo et al., 1996; 2001).

The correct extraction of ticks should be done using thin-tipped tweezers or blunt, rounded forceps introducing them between tick head and the skin to grasp the mouth parts of ticks intact if possible. Pull the tick straight upward with steady pressure, perpendicular to the skin (Oteo et al., 2001; Parola and Raoult, 2001; Stafford, 2004) (Fig. 5). If after the extraction any part of the tick is retained in the skin it should be advisable to perform a biopsy of the inoculation place in order to avoid a neurotoxic paralysis due to the presence of the arthropod salivary glands and the neurotoxin in the patient (Oteo et al., 1990; 2001). After removal of the tick the skin area should be disinfected with povidone iodine or other skin disinfectant. Commercially available tick removal devices have been shown being useful for removing nymphal stages, especially to successfully remove I. scapularis nymphs (Parola and Raoult, 2001; Stafford, 2004). Ticks removed should be stored at $-20^{\circ} \mathrm{C}$ for future analyses for the detection or isolation of the causative agent in case of the patient develops an infectious disease (Parola and Raoult, 2001).

\subsection{Antibiotic Prophylaxis After Tick Bite}

There is not a consensus about the use of antibiotic prophylaxis after tick bites. Usually, most of tick bites do not cause any complication, except mild local pruritic inflammatory reactions of short duration. Guidelines carry out by the Infectious Diseases Society of America (IDSA) in 2000 do not recommend the routine use of chemoprophylaxis for the prevention of Lyme disease (Wormser et al., 2000). The Centers for Disease Control and Prevention (CDC) do not recommend the routine use of antibiotic prophylaxis for the tick-borne infections (CDC, 1991). 


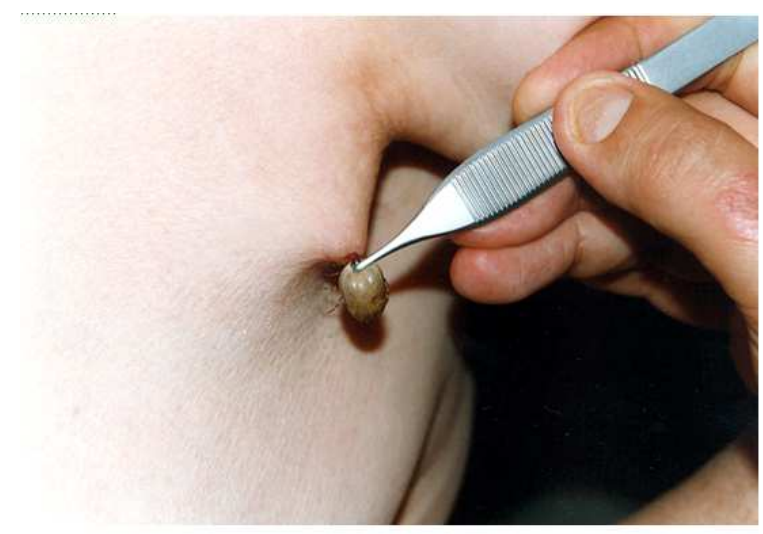

Fig. 5. Extraction of a Hyalomma marginatum female from a patient

Due to the possibility of complications most of the studies in relationship with this topic have been made regarding to Lyme disease (Oteo et al., 2001) A study carried out by Warshafsky et al. (1996) suggest that the antibiotics used for the prophylaxis showed more adverse effects than the benefits that they may cause. They also published that only one case was prevent of Lyme borreliosis of each 83 patients treated with antibiotics as prophylactic measure. In the case of using doxycycline as prophylaxis measure for Lyme borreliosis, that administration of the antibiotic should be done in the first $48 \mathrm{~h}$ after the tick bite in order to avoid the entrance of the spirochete according to studies carried out in an animal model (Shilh et al., 1992). Other authors demonstrated an $87 \%$ of effectiveness for the prophylaxis of Lyme borreliosis with a single dose of doxycycline in an endemic area from North America, fact that motivated the published of an editorial based on the use of topic antibiotics for the prevention on Lyme disease (Nadelman et al., 2001; Shapiro, 2001). Studies carried out by our group with topic oxytetracycline $2 \%$ show significant differences versus the topic administration of vaseline. The patients who administrated topic oxytetracycline twice a day for two days do not developed infection or related disease (Oteo et al., 1998).

Donovan et al. (2002) suggest that the use of a single dose of doxycycline, according to its efficacy and mild adverse effects, should be limited to areas with high risk of exposure (Donovan et al., 2002). Other authors also say that the use of weekly doses of prophylactic doxycycline can prevent scrub typhus infection in endemic areas (Olson et al., 1980; Twartz et al., 1982). However, the use of chemoprophylaxis is uncertain to prevent the acquisition of other rickettsioses. Although some papers suggest that the use of prophylactic antibiotics, especially doxycycline, reduce the risk of tick borne diseases, there are controversial data to ensure that the prophylaxis is beneficial for patients to prevent rickettsioses or Lyme disease (Dobler, 2010). Despite all these studies, is important to consider that the use of prophylactic antibiotics depends on the degree of tick engorgement and the time of attachment of the tick (Oteo et al., 2001; Parola and Raoult, 2001). The risk of infection of B. burgdorferi is higher when the tick has been attached more than 48-72 h. However ehrlichial and rickettsial infections can be transmitted in few hours. Lamentably, in most cases, is not possible to asses those aspects (Piesman et al., 1987; Piesman, 1993; Sood et al., 1997; Des Vignes et al., 2001).

In our experience, we do not advise the general use of antibiotics for the prophylaxis of tick bites. However, when the tick has been manipulated, the tick is engorged or the patient has a high level of anxiety, the prophylaxis with doxycycline could be offered (Oteo et al., 1996).

\section{CONCLUSION}

The best way for preventing tick-borne diseases is to avoid tick bites. There are several pre-exposition and postexposition measures that can be effective and usseful to decrease tick-bites and tick related disorders. Wearing apropiate clothing, using repelents, looking for tick attaches and an early apropiatte removal have been used with different grades of succes. Interventions in hosts and in selected infested areas to control tick populations can also be performed. There are few evidences to extend the use of antimicrobials after tick-bites as prophilaxis.

\section{REFERENCES}

Ahoussou, S., R. Lancelot, B. Sanford, T. Porphyre and P. Bartlette-Powell et al., 2010. Analysis of Amblyomma surveillance data in the Caribbean: Lessons for future control programmes. Vet. Parasitol., 167: 327-335. DOI: 10.1016/j.vetpar.2009.09.035

Allan, B.F., 2009. Influence of prescribed burns on the abundance of Amblyomma americanum (Acari: Ixodidae) in the missouri ozarks. J. Med. Entomol., 46: 1030-1036. PMID: 19769033

Aronowitz, R.A., 2012. The rise and fall of the lyme disease vaccines: A cautionary tale for risk interventions in American medicine and public health. Milbank Q., 90: 250-277. DOI: 10.1111/j.1468-0009.2012.00663.x 
Bavaro, M.F., D.J. Kelly, G.A. Dasch, B.R. Hale and P. Olson, 2005. History of U.S. military contributions to the study of rickettsial diseases. Military Med., 170: 49-60. PMID: 15916283

Berrada, Z.L. and S.R. Telford, 2009. Topics in companion. Anim. Med., 24: 175-181. DOI: 10.1053/j.tcam.2009.06.005

Beugnet, F. and J.L. Marie, 2009. Emerging arthropodborne diseases of companion animals in Europe. Vet. Parasitol., 163: 298-305. DOI: 10.1016/j.vetpar.2009.03.028

CDC, 1991. Antibiotic prophylaxis of lyme disease following recognized tick bite. Bacterial zoonoses branch, division of vector-borne infectious diseases national center for infectious diseases, centers for disease control. Conn. Med., 55: 691-693. PMID: 1790707

CDC, 1999. Recommendations for the Use of Lyme Disease Vaccine Recommendations of the advisory Committee on Immunization Practices (ACIP). MMWR, 48: 1-17.

Clark, R.P. and L.T. Hu, 2008. Prevention of Lyme disease and other tick-borne infections. Infect. Dis. Clin. North Am., 22: 381-396. DOI: 10.1016/j.idc.2008.03.007

Daltroy, L.H., C. Phillips, R. Lew, E. Wright and N.A. Shadick et al., 2007. A controlled trial of a novel primary prevention program for Lyme disease and other tick-borne illnesses. Health Educ. Behav., 34: 531-542. PMID: 17468463

Dantas-Torres, F., B.B. Chomel and D. Otranto, 2012. Ticks and tick-borne diseases: A one health perspective. Trends Parasitol., 28: 437-446. DOI: 10.1016/j.pt.2012.07.003

Day, M.J., 2011. One health: The importance of companion animal vector-borne diseases. Parasit. Vect., 4: 49-49. DOI: 10.1186/1756-3305-4-49

De Silva, A.M. and E. Fikrig, 1995. Growth and migration of Borrelia burgdorferi in Ixodes ticks during blood feeding. Am. J. Tropical Med. Hygiene, 53: 397-404. PMID: 7485694

Des Vignes, F., J. Piesman, R. Hefferman, T.L. Schhulze and D. Fish et al., 2001. Effect of tick removal on transmission of Borrelia burgdorferi and Ehrlichia phagocytophila by Ixodes sacapularis nymphs. J. Infect. Dis., 183: 773-778. PMID: 11181154

Dobler, G., 2010. Zoonotic tick-borne flaviviruses. Vet. Microbiol., 140: 221-228. DOI: 10.1016/j.vetmic.2009.08.024
Donovan, B.R., D.J. Weber, J.C. Rublein and R.H. Raasch, 2002. Treatment of tick-borne diseases. Annals Pharmacotherapy, 36: 1590-1597. PMID: 12243610

Drew, M.L., W.M. Lutiwski and J.N. Willman, 1985. An evaluation of burning for control of winter ticks, Dermacentor albipictus, in central Alberta. J. Wildlife Dis., 21: 313-315. PMID: 4032634

Dryden, M.W. and P.A. Payne, 2004. Biology and control of ticks infesting dogs and cats in North Am. Vet. Therapeut., 5: 139-154. PMID: 15468011

George, J.E., J.M. Pound and R.B. Davey, 2004. Chemical control of ticks on cattle and the resistance of these parasites to acaricides. Parasitology, 129: S353-S366. PMID: 15938518

Halos, L., G. Baneth, F. Beugnet, A.S. Bowman and B. Chomel et al., 2012. Defining the concept of 'tick repellency' in veterinary medicine. Parasitology, 139: 419-423. DOI: 10.1017/S0031182011002228

Hoch, A.L., P.J. Semtner, R.W. Baker and J.A. Hair, 1972. Preliminary observation on controlled burning for lone star tick (Acarina: Ixodidae) control in woodlots. J. Med. Entomol., 9: 446-451. PMID: 5080432

Hojgaard, A., R.J. Eisen and J. Piesman, 2008. Transmission dynamics of Borrelia burgdorferi s.s. during the key third day of feeding by nymphal Ixodes scapularis (Acari: Ixodidae). J. Med. Entomol., 45: 732-736. PMID: 18714875

Horka, H., K. Cerna-Kyckova, A. Skallova and J. Kopecky, 2009. Tick saliva affects both proliferation and distribution of Borrelia burgdorferi spirochetes in mouse organs and increases transmission of spirochetes to ticks. Int. J. Med. Microbiol., 299: 373-380. DOI: 10.1016/j.ijmm.2008.10.009

Hubalek, Z., 2004. An annotated checklist of pathogenic microorganisms associated with migratory birds. J. Wildlife Dis., 40: 639-659. PMID: 15650082

Jordan, R.A., T.L. Schulze and M.B. Jahn, 2007. Effects of reduced deer density on the abundance of Ixodes scapularis (Acari: Ixodidae) and Lyme disease incidence in a northern New Jersey endemic area. J. Med. Entomol., 44: 752-757. PMID: 17915504

Katavolos, P., P.M. Armstrong, J.E. Dawson and S.R. Telford, 1998. Duration of tick attachment required for transmission of granulocytic ehrlichiosis. J. Infect. Dis., 177: 1422-1425. PMID: 9593039 
Korenberg, E.I. and Y.V. Kovalevskii, 1999. Main features of tick-borne encephalitis eco-epidemiology in Russia. Zentralblatt für Bakteriol., 289: 525-539. PMID: 10652719

Krober, T. and P.M. Guerin, 2007. In vitro feeding assays for hard ticks. Trends Parasitol., 23: 445-449. PMID: 17681859

Labruna, M.B., S. Mattar, S. Nava, S. Bermudeza and J.M. Venzal et al., 2011. Rickettsioses in Latin America, Caribbean, Spain and Portugal. Revista MVZ Córdoba, 16: 2435-2457.

Lindsay, L.R., I.K. Barker, G.A. Surgeoner, S.A. McEwen and G.D. Campbell, 1997. Duration of Borrelia burgdorferi infectivity in white-footed mice for the tick vector Ixodes scapularis under laboratory and field conditions in Ontario. $\mathrm{J}$. Wildlife Dis., 33: 766-775. PMID: 9391960

Ma, J., P.M. Hine, E.R. Clough, D. Fish and R.T. Coughlin et al., 1996. Safety, efficacy and immunogenicity of a recombinant Osp subunit canine Lyme disease vaccine. Vaccine, 14: 13661374. PMID: 9004447

Malouin, R., P. Winch, E. Leontsini, G. Glass and D. Simon et al., 2003. Longitudinal evaluation of an educational intervention for preventing tick bites in an area with endemic Lyme disease in Baltimore County, Maryland. Am. J. Epidemiol., 157: 10391051. PMID: 12777368

Marquez-Jimenez, F.J., A. Hidalgo-Pontiveros, F. Contreras-Chova, J.J. Rodriguez-Liebana and M.A. Muniain-Ezcurra, 2005. Ticks (Acarina: Ixodidae) as vectors and reservoirs of pathogen microorganisms in Spain. Enfermedades Infecc. Microbiol. Clin., 23: 94-102. PMID: 15743581

Mather, T.N., D.C. Duffy and S.R. Campbell, 1993. An unexpected result from burning vegetation to reduce Lyme disease transmission risks. J. Med. Entomol., 30: 642-645. PMID: 8510127

Matuschka, F.R. and A. Spielman, 1992. The vector of the Lyme disease spirochete. N. Engl. J. Med., 327: 542-542. PMID: 1635568

Mendes, M.C., C.K. Lima, A.H. Nogueira, E. Yoshihara and D.P. Chiebao et al., 2011. Resistance to cypermethrin, deltamethrin and chlorpyriphos in populations of Rhipicephalus (Boophilus) microplus (Acari: Ixodidae) from small farms of the State of São Paulo, Brazil. Vet. Parasitol., 178: 383-388. DOI: 10.1016/j.vetpar.2011.01.006
Miller, N.J., E.E. Rainone, M.C. Dyer, M.L. Gonzalez and T.N. Mather, 2011. Tick bite protection with permethrin-treated summer-weight clothing. J. Med. Entomol., 48: 327-333. PMID: 21485369

Miller, R.S., M.L. Farnsworth and J.L. Malmberg, 2012. Diseases at the livestock-wildlife interface: Status, challenges and opportunities in the United States. Preventive Vet. Med., 110: 119-132. DOI: 10.1016/j.prevetmed.2012.11.021

Mondal, D.B., K. Sarma and M. Saravanan, 2013. Upcoming of the integrated tick control program of ruminants with special emphasis on livestock farming system in India. Ticks Tick-borne Dis., 4: 110. DOI: 10.1016/j.ttbdis.2012.05.006

Nadelman, R.B., J. Nowakowski, D. Fish, R.C. Falco and K. Freeman et al., 2001. Prophylaxis with songle-dose doxycyclinefor the prevention of Lyme disease after an Ixodes scapularis tick bite. New Engl. J. Med., 345: 79-84. PMID: 11450675

Olson, J.G., A.L. Bourgeois, R.C. Fang, J.C. Coolbaugh and D.T. Dennis, 1980. Prevention of scrub typhus: Prophylactic administration of doxycycline in a randomized double-blind trial. Am. J. Tropical Med. Hygiene, 29: 989-997. PMID: 7435798

Oteo, J.A. and A. Portillo, 2012. Tick-borne rickettsioses in Europe. Ticks Tick-borne Dis., 3: 271-278. DOI: 10.1016/j.ttbdis.2012.10.035

Oteo, J.A. and P. Brouqui, 2005. Ehrlichiosis and human anaplasmosis. Enfermedades Infecc. Microbiol. Clin., 23: 375-380. PMID: 15970171

Oteo, J.A., E. Maravi, V.M. de Artola and P. Antunano, 1990. Paralysis caused by tick bite. Med. Clin. (Barcelona), 94: 275-276. PMID: 2325490

Oteo, J.A., J. Ruiz-Soria, V. Martínez de Artola, I. Torroba and J.M. Casas et al., 1998. VS placebo topical tetracycline after tick bites for the prevention of Lyme borreliosis. A randomized, double-blind randomized. Proceedings of the National Meeting of the Working Group Rickettsia and Borrelia, Oct. 2830, Haro La Rioja, Spain.

Oteo, J.A., J.R. Blanco and V. Ibarra, 2001. Can we prevent tick-borne transmitted diseases. Enfermedades Infecc. Microbiol. Clin., 19: 509-513. PMID: 11844465

Oteo, J.A., V.M. de Artola, R. Gomez-Cadinanos, J.M. Casas and J.R. Blanco et al., 1996. Evaluation of methods of tick removal in human ixodidiasis. Revista Clin. Espanola, 196: 584-587. PMID: 8966318 
Palomar, A.M., A. Portillo, P. Santibanez, D. Mazuelas and J. Arizaga et al., 2013. Crimean-Congo hemorrhagic fever virus in ticks from migratory birds, Morocco. Emerg. Infect. Dis., 19: 260-263. DOI: $10.3201 /$ eid1902.121193

Palomar, A.M., P. Santibanez, D. Mazuelas, L. Roncero and S. Santibanez et al., 2012. Role of birds in dispersal of etiologic agents of tick-borne zoonoses, Spain, 2009. Emerg. Infect. Dis., 18: 1188-1191. DOI: $10.3201 /$ eid1807.111777

Parola, P. and D. Raoult, 2001. Ticks and tickborne bacterial diseases in humans: An emerging infectious threat. Clin. Infect. Dis., 32: 897-928. PMID: 11247714

Parola, P., C. Socolovschi, L. Jeanjean, I. Bitam and P.E. Fournier et al., 2008. Warmer weather linked to tick attack and emergence of severe rickettsioses. PLoS Neglected Tropical Dis., 2: e338-e338. DOI: 10.1371/journal.pntd.0000338

Parola, P., C.D. Paddock and D. Raoult, 2005. Tickborne rickettsioses around the World: Emerging diseases challenging old concepts. Clin. Microbiol. Rev., 18: 719-756. PMID: 16223955

Piesman, J. and L. Eisen, 2008. Prevention of tick-borne diseases. Ann. Rev. Entomol., 53: 323-343. PMID: 17877457

Piesman, J., 1993. Dynamics of Borrelia burgdorferi transmission by nynphal Ixodes dammini ticks. J. Infect. Dis., 167: 1082-1085. PMID: 8486940

Piesman, J., 2006. Strategies for reducing the risk of Lyme borreliosis in North America. Int. J. Med. Microbiol., 296: 17-22. PMID: 16524769

Piesman, J., T.N. Mather, R.J. Sinsky and A. Speilman, 1987. Duration of tick attachment and Borrelia burgdorferi transmission. J. Clin. Microbiol., 25: 557-558. PMID: 3571459

Poland, G.A., 2011. Vaccines against Lyme disease: What happened and what lessons can we learn? Clin. Infect. Dis., 52: s253-s258. DOI: 10.1093/cid/ciq116

Rand, P.W., C. Lubelczyk, M.S. Holman, E.H. Lacombe and R.P. Smith, 2004. Abundance of Ixodes scapularis (Acari: Ixodidae) after the complete removal of deer from an isolated offshore island, endemic for Lyme Disease. J. Med. Entomol., 41: 779-784. PMID: 15311475

Rogers, A.J., 1953. A study of the ixodid ticks of northern Florida, including the biology and life history of Ixodes scapularis. Ph.D. Dissertation, University of Maryland, College Park.
Samish, M. and J. Rehacek, 1999. Pathogens and predators of ticks and their potential in biological control. Ann. Rev. Entomol., 44: 159-182. PMID: 9990719

Schetters, T., 2005. Vaccination against canine babesiosis. Trends Parasitol., 21: 179-184. PMID: 15780840

Schetters, T.P., J. Kleuskens, B. Carcy, A. Gorenflot and A. Vermeulen, 2007. Vaccination against large Babesia species from dogs. Parassitologia, 49: 1317. PMID: 17691601

Schetters, T.P., J.A. Kleuskens, N.C. Scholtes, J.W. Pasman and D. Goovaerts, 1997. Vaccination of dogs against Babesia canis infection. Vet. Parasitol., 73: 35-41. PMID: 9477490

Schulze, T.L., G.C. Taylor, L.M. Vasvary, W. Simmons and R.A. Jordan, 1992. Effectiveness of an aerial application of carbaryl in controlling Ixodes dammini (Acari: Ixodidae) adults in a high-use recreational area in New Jersey. J. Med. Entomol., 29: 544-547. PMID: 1625304

Schulze, T.L., R.A. Jordan and A.J. Krivenko, 2005. Effects of barrier application of granular deltamethrin on subadult Ixodes scapularis (Acari: Ixodidae) and nontarget forest floor arthropods. J. Econ. Entomol., 98: 976-981. PMID: 16025588

Schulze, T.L., R.A. Jordan, C.J. Schulze and S.P. Healy, 2008. Suppression of Ixodes scapularis (Acari: Ixodidae) following annual habitat-targeted acaricide applications against fall populations of adults. J. Am. Mosquito Control Assoc., 24: 566570. PMID: 19181066

Schulze, T.L., R.A. Jordan, C.J. Schulze, S.P. Healy and M.B. Jahn et al., 2007. Integrated use of 4-Poster passive topical treatment devices for deer, targeted acaricide applications and Maxforce TMS bait boxes to rapidly suppress populations of Ixodes scapularis (Acari: Ixodidae) in a residential landscape. J. Med. Entomol., 44: 830-839. PMID: 17915516

Schulze, T.L., R.A. Jordan, L.M. Vasvary, M.S. Chomsky and D.C. Shaw et al., 1994. Suppression of Ixodes scapularis (Acari: Ixodidae) nymphs in a large residential community. J. Med. Entomol., 31: 206-211. PMID: 17915516

Shapiro, E.D., 2001. Doxycycline for tick bites-not for everyone. New England J. Med., 345: 133-134. PMID: 11450662

Shaw, S.E., M.J. Day, R.J. Birtles and E.B. Breitschwerdt, 2001. Tick-borne infectious diseases of dogs. Trends Parasitol., 17: 74-80. PMID: 11228013 
Shen, A.K., P.S. Mead and C.B. Beard, 2011. The Lyme disease vaccine--a public health perspective. Clin. Infect. Dis., 3: s247-s252. DOI: 10.1093/cid/ciq115

Shilh, C.M., R.J. Pollack, S.R. Telford and A. Spielman, 1992. Delayed dissemination of Lyme disease spirochetes from the site of deposition in the skin of mice. J. Infect. Dis., 166: 827-831. PMID: 1527418

Sigal, L.H., J.M. Zahradnik, P. Lavin, S.J. Patella and G. Bryant et al., 1998. Malawista. A vaccine consisting of recombinant Borrelia burgdorferi outer-surface protein A to prevent Lyme disease. Recombinant outer-surface protein a lyme disease vaccine study consortium. New England J. Med., 339: 216-222. PMID: 9673299

Smith, C.N., M.M. Cole and H.K. Gouck, 1946. Biology and control of the American dog tick. USDA Tech. Bull.

Sonenshine, D.E., 2004. Pheromones and other semiochemicals of ticks and their use in tick control. Parasitology, 129: S405-S425. PMID: 15938521

Sonenshine, D.E., 2006. Tick pheromones and their use in tick control. Ann. Rev. Entomol., 51: 557-580. PMID: 16332223

Sood, S.K., M.B. Salzman, B.J. Johnson, C.M. Happ and K. Feig et al., 1997. Duration of tick attachment as a predictor of the risk of Lyme disease in an area in which Lyme disease is endemic. J. Infect. Dis., 175: 996-999. PMID: 9086168

Stafford, K.C., 1991. Effectiveness of carbaryl applications for the control of Ixodes dammini (Acari: Ixodidae) nymphs in an endemic residential area. J. Med. Entomol., 28: 32-36. PMID: 1903451

Stafford, K.C., 2004. Tick Management Handbook. An integrated guide for homeowners, pest control operators and public health officials for the prevention of tick-associated disease. The Connecticut Agricultural Experiment Station.

Stafford, K.C., J.S. Ward and L.A. Magnarelli, 1998. Impact of controlled burns on the abundance of Ixodes scapularis (Acari: Ixodidae). J. Med. Entomol., 35: 510-513. PMID: 9701937

Steere, A.C., 2001. Lyme disease. New England J. Med., 345: 115-125. PMID: 11450660

Steere, A.C., V.K. Sikand, F. Meurice, D.L. Parenti and E. Fikrig et al., 1998. Vaccination against Lyme disease with recombinant Borrelia burgdorferi outer-surface lipoprotein A with adjuvant. Lyme Disease Vaccine Study Group. New England J. Med., 339: 209-215. PMID: 9673298
Twartz, J.C., A. Shirai, G. Selvaraju, J.P. Saunders and D.L. Huxsoll et al., 1982. Doxycycline prophylaxis for human scrub tiphus. J. Infect. Dis., 146: 811818. PMID: 6815282

Vaughn, M.F. and S.R. Meshnick, 2011. Pilot study assessing the effectiveness of long-lasting permethrin-impregnated clothing for the prevention of tick bites. Vector Borne Zoonotic Dis., 11: 869875. DOI: $10.1089 / \mathrm{vbz} .2010 .0158$

Vazquez, M., C. Muehlenbein, M. Cartter, E.B. Hayes and S. Ertel et al., 2008. Effectiveness of personal protective measures to prevent Lyme disease. Emerg. Infect. Dis., 14: 210-216. DOI: 10.3201/eid1402.070725

Walker, A.R., 2011. Eradication and control of livestock ticks: Biological, economic and social perspectives. Parasitology, 138: 945-959. DOI: 10.1017/S0031182011000709

Walker, D.H., C.D. Paddock and J.S. Dumler, 2008. Emerging and re-emerging tick-transmitted rickettsial and ehrlichial infections. Med. Clin. North Am., 92: 1345-1361. DOI: 10.1016/j.mcna.2008.06.002

Warshafsky, S., J. Nowakowski, R.B. Nadelman, R.S. Kamer and S. Peterson et al., 1996. Efficacy of antibiotic prophylaxis for prevention of Lyme borreliosis. J. General Int. Med., 11: 329-333. PMID: 8803738

WHO, 1992. Vector resistance to pesticides. Fifteenth report of the who expert committee on vector biology and control. World Health Organ. Tech. Rep. Series, 818: 1-62. PMID: 1574907

Wilson, M.L., 1986. Reduced abundance of adult Ixodes dammani (Acari: Ixodidae) following destruction of vegetation. J. Econ. Entomol., 79: 693-696. PMID: 3722593

Wormser, G.P., R.B. Nadelman, R.J. DAttwyler, D.T. Dennis and E.D. Shapiro et al., 2000. Practice guidelines for the treatment of Lyme disease. The Infectious Diseases Society of America. Clin. Infect. Dis., 31: S1-S14. PMID: 10982743

Zivkovic, Z., A.M. Nijhof, J. de la Fuente, K.M. Kocan and F. Jongejan, 2007. Experimental transmission of Anaplasma marginale by male Dermacentor reticulatus. BMC Vet. Res., 3: 32-32. PMID: 18053123 